\title{
Digital Natives or Digital Tribes?
}

\author{
Ian Robert Watson
}

Faculty of Engineering and Environment, Northumbria University, UK

*Corresponding Author: i.watson@northumbria.ac.uk

Copyright (C) 2013 Horizon Research Publishing All rights reserved.

\begin{abstract}
This research builds upon the discourse surrounding digital natives. A literature review into the digital native phenomena was undertaken and found that researchers are beginning to identify the digital native as not one cohesive group but of individuals influenced by other factors. Primary research by means of questionnaire survey of technologies used by students in three countries was carried out. Findings identify a number of differences in the technologies preferred by students for education and those used in their social lives. From being one digital native, it may be clearer to look to the culture and region of where the student lives and is educated and the 'tribe' they belong to rather than assume there is one digital native population.
\end{abstract}

Keywords Digital natives, digital immigrants, digital tribes

\section{Introduction}

Since the term 'digital natives' was popularised by Marc Prensky [1] there has been an on-going discussion and evaluation of the term. The debate around the digital native has progressed over the last twelve years, with some researchers believing that since the natives exist education must change to address this [2] and other investigators taking a more impartial approach and asking if the natives do exist as discussed by Prensky [3-5]. Research into the latter has identified a body of evidence to suggest there is a difference in use of technologies, not solely based on the year of birth of the student, but based on their nationality and the educational system in which they grow up $[6,7]$.

This research paper aims to look to this continuation of the digital native debate and answer two questions, 'do digital natives in 2013 exist as defined by Prensky in 2001?' and 'Is there a difference in use of technologies between digital natives of different nationalities?' The first question will be investigated by an in depth review of recent literature, the second by analysis of a questionnaire distributed to three different groups of students, from the United Kingdom, Malaysia and South Korea.

\section{Literature Review}

This literature review begins by looking at the digital native/digital immigrant debate and questioning ifwhat teaching staff think students want from education, differs from what the learners actually want; the two, teacher and learner may not be speaking the same digital language, as one is the digital immigrant and the other the digital native. Are the technologies used by digital natives really what the learner wants/needs or is it just what academics and support staff think they want because we class the potential users of the tool as digital natives? It might be better to look at the experience and breadth of use of technologies by students, rather than to just assume the educator knows best. What this work will do is to investigate the technologies that the students in three different countries use.

The students in this study will by definition be 'digital natives' by virtue of when they were born (see Figure 1), and their teacher largely digital immigrants.

One of the propositions of Prensky was that "today's students think and process information fundamentally differently from their predecessors", however research by authors [3] suggests that the brains of digital immigrants in the age bracket $55-70$ were as stimulated as the digital natives - the immigrant had never searched for information online, but after a week of using the internet their brains had developed and were as active as the control group who had always searched for information online. There are still researchers that accept this neuroplasticity of the brain [8], so it clear that there is still a degree of research to undertake to critically evaluate the digital native definition. However not all researchers support the contention of the digital native being 'wired in' to technology and needing an immediate response or reply to their query. There is a body of evidence that purports to discredit the view of the digital natives and their obsession with technology $[2,4,5,9,10,11]$ accepts that the digital native exists as described by Prensky "This new generation ... approaches learning and living in new ways for instance they assume connectivity and see the world through the lens of games and play" [1].Then goes on to quote Prensky in the areas of multitasking, better parallel processing, thinking graphically and 'the learning preferences of digital natives include the use of technology, interactions, team working etc.." . There is no acceptance that it is possible to challenge the digital native term as was first coined over a decade ago. Instead it is assumed and 
accepted that the digital native exists based upon their decade of birth. But there is a body of evidence to suggest that there are differences in the digital natives depending upon other factors rather than just when they were born. For instance their place of birth and their nationality, [6] carried out a survey of just under 12000 students (aged 15 -24) in Asia, these included Indian, Chinese, Thai, Indonesian and Malay students, differences were evident within the survey, e.g. Web 2.0 application use varied from country to country, in Thailand students spent four times as long on email activity than those in India. In all cases students multitasked, emailed, listening to music, updating social networking sites etc. to the extent that some students managed to squeeze 38 hours of activity into one 24 hour period. This multitasking can be seen as a double edged sword - and begs the question does multitasking make the digital natives more productive or less? Some authors [12] found that though the traditional definition of the digital native applied to the students in their study, that the competency of these students varied in several areas, such as schools the students attended and had no relation to if the students owned a personal computer. Others [13] define digital natives in a manner outside of their year of birth, looking to their feelings, descriptions and behaviours about their online activity - their year of birth is added as a supplement their digital nativism as an indicator. Their findings suggest that digital natives were less likely to personally exchange information with classmates and to solve problems themselves without prompting, guidance and encouragement, though less technically confident than the digital natives the digital immigrants were more self-confident and better at knowledge application than the younger students, probably due to their greater experience of work and with knowledge transfer. A further move away from the digital native and their year of birth is by means of looking at the use of technology. The breadth of use of technology both in education and outside of education is investigated [5] 'experience in using the Internet and breadth of use are good indicators of whether someone is a digital native or not'. This definition backs up that of others $[6,13]$ in that it is not just the breadth of technology used that should define the digital natives but their depth of use of the technology. By looking just at the age of an individual there are other relevant (and missing) aspects of the digital natives that needs to be taken into account, for instance, education, class, culture and gender. In a survey of Italian students [7] found that the impact of the education of the parents of the digital natives 'could produce significant differences in the possession of digital skills', so looking to the definition of digital natives and their breadth of technology use and their upbringing. Work such as this demonstrates that it is not right to accept Prensky's literal definition and that there are other aspects to take into consideration instead of classifying people as digital natives or digital immigrants based on when they were born. Some [14] see a change in attitude and a categorizing of generations based on their choices of music and fashion to the threat of technology as a means of classifying/categorizing a generation. The digital natives could be seen within their own distinct era just as in past decades mods, punks and new romantics were identified by their own fashions and music.

There is some research that still sees the digital natives as an isolated generation much different than those that came before. [9] to some extent falls into this category, in that he looks to academic libraries having to change the way they provide services to a new generation of students. He does however take the view that all people born after a certain date fall into the category of digital natives and that libraries must change to meet the needs of this new generation, because technology is used in the social side of a young person's life that it should also be available to them (and predicted to be used) in their education, for instance the development by 'library management system vendors are now making to design in 2.0 features such as faceted search'. Others see the digital native/digital immigrant ideas of Prensky as a way education has to look forward and adapt to meet the differences in the digital native/immigrant debate for instance [8] where since students have grown up with technologies they are expecting to use these technologies in their education. Researchers who fall in the 'Prensky impartial' camp include $[15,16]$ the latter accept the term digital natives and looked at the digital natives in the workplaces (as if they were born in 1980s they are now in or approaching their 30s) and found that they separated their social and workplace lives. Employees preferred to use social media not in the workplace, but in their social and private live, at work they preferred to use traditional internal communication channels such as employees meetings and e-mail newsletters rather than social media.

There have been several studies in recent years into the technology use of students in their private lives as compared to their academic lives, $[4,17,18]$ all illustrating that there are indeed differences in use between the two.

This study looks to take this work a step further and compare this technological use at an international level.

\section{Methodology}

The survey employed a quantitative methodology approach; a questionnaire was given to students willing to participate in the survey. In Malaysia the questionnaire was distributed in class, in S. Korea and the UK students were invited to participate in the study by lecturers, and volunteers were emailed a copy of the questionnaire. The questionnaire was an adaptation of that of [4], see appendix one for a copy of the questionnaire.

All students were aged between 19 and 25 the classification of the students under the age bracket does not necessarily mean all use technology or want to use the technologies available to them to the same degree, both in their social lives and their educational uses of technology. A norm may be evident form the answers to the surveys which might indicate what is culturally acceptable or normal for that group of students in that country - any differences between countries in use or wanting to use the technologies 
will be evident. There is already some regionalism in the literature to suggest that this might be the case [6].

\section{Discussion of Findings}

When the questionnaires were analysed the majority of respondents were male, with only 26 females out of a total of 154 (less than 17\%). This concurs with research into the gender differences on undergraduate computer science courses (for instance [19] where the figure of $20 \%$ is stated. Technologies used on their programmes of study are equal at a mean of 13 for Malaysia and the UK with South Korea at 14. This suggests that the teaching on these programmes is generally equal in the technologies employed by their educators - the digital immigrants.

Technologies used for their own learning were similar to that of the hardware technologies used by students in that Malaysia and South Korea had approximately the same with a mean of 10.6 and 10.7, but those employed by the UK students themselves was higher at 11.9.

Malaysian and Korean students used approximately the same number of hardware technologies, at an average of 3.4 and 3.1 respectively. Students from the UK used more technologies at a mean of 4.6.

For the hardware technologies used by students, not covered by the previous sections, again Malaysia and South Korean students used approximately the same at 8.0 and 8.4 respectively. The UK students however used fewer technologies at 7.3.

\section{Hardware owned and used on a regular basis.}

An average of $93 \%$ of students owned a mobile phone, but only $85 \%$ of Malaysian students owned the device (see table 3 which summarises the responses by country). There was a similar finding in ownership and use of portable media players with $67 \%$ of UK students using the technology, but only $20 \%$ of Malaysians. However the ownership of handheld computers was quite different with only $2 \%$ of South Korean students using this technology and the UK and Malaysia on $39 \%$ and $25 \%$ respectively. The biggest difference in technology ownership was found with that of games technologies $0 \%$ of $\mathrm{S}$. Koreans possessed either portable or desktop games consoles compared to the UK where over $50 \%$ possessed a console.

\section{Electronic tools used by students on their programmes of study}

When students were asked about their use of electronic tools used on their programmes it was found that the most used tools were course websites with S. Korea at $100 \%$ usage, Malaysia at $98 \%$ and the UK at $90 \%$. Only discussion groups used on courses also played an important part in student to all three sites with usage of over $70 \%$.

Other popular technologies were mobile phones, but only by the UK (75\%) the other sites of Malaysia and S. Korea only $35 \%$ and $37 \%$ respectively. Internet websites, Google
Scholar and Wikipedia are highly used as tools for use on courses. Several technologies fell into the $50 \%$ usage bracket $(+/-10 \%)$, chat, MP3, handheld computer. There are evidently differences in use of some technologies between universities and their students, for instance in the use of podcasts varied widely between the three centres, with $75 \%$ of students in the UK using this technology and only $35 \%$ and $37 \%$ respectively in Malaysia and S. Korea. A similar difference in the use of technology was found in use of MySpace with $41 \%$ of S. Korean student using this and only $20 \%$ and $13 \%$ in Malaysia and the UK. Weblog use too varied with only $37 \%$ of Malaysian students using blogs to $74 \%$ in the UK.

\section{Technology used for students own learning in relation to their course but not provided by their University}

These are the tools used by students in their studies but are not provided by their institution, so are not 'pushed' but are 'pulled' (chosen) by the students themselves to help in their studies. As in the previous section, the use of mobiles phones rated highly in all three sites as did the use of YouTube and Google Scholar. Several technologies rated low in all three countries in this category, MySpace, Second life and MP3 player were all less than $1 / 3$ use in each University. There were several differences evident from the three sites, for instance blogs and message board use was significantly lower in Malaysia than in either South Korea or the UK.

\section{Use of technology and software other than that detailed above}

Several tools were used regularly at all three sites, music and photo upload, Social Networking; wikis were all above the $75 \%$ usage level. Several sites demonstrated a higher use than others, for instance blogging was not popular with Malaysian students, (21\%) but more so in South Korea and the UK (54\%). The use of chat rooms however in Malaysia was higher at $76 \%$ than in the other two Universities (both $46 \%$ ). The biggest difference however was in technology use was found with internet gaming with $70 \%$ of S. Koreans using this software compared to only $47 \%$ (Malaysia) and $44 \%$ (UK).

\section{Discussion}

It is clear from the findings that there are differences in technology use between the three Universities. Some of these are as a result of the technologies used by their institutions, for example with the use of blogs, twice as many UK students used this than Malaysian students.

In students wonting and using technologies on a regular basis it is evident that handheld and laptop computers are not as popular in S. Korea than at the other two countries - this might be linked to the use in S. Korea and internet gaming (70\% compared with Malaysia 44\%). Online gaming needs more processing power than that of either games consoles or portable games machines as S. Korea responded to zero in 
the latter two categories. MMORPG games are very popular in S. Korea so this may account for the differences [20].

There are some similarities that students find in common, the use of internet sites and Google Scholar, but also specific such as message boards provided by their University which seem to be used more frequently than in other countries. But electronic tools not pushed by University to help with students are seen as 'pull' as they are chosen/selected by the students themselves to aid their studies, so it could be that these are more important technologies to students than those provided by their institution. If they were equally as important as institution provided tools then their use should be the same. Perhaps equally significant is the use of student technologies other than those mentioned in connection to their studies. These are the 'pull' technologies whereby students use them in their everyday life, i.e. for recreational use. The use of music for instance is much higher for social/recreational use than in study (this should not come as a surprise as all three programmes were non music based), but it would be difficult to include a music element to computer science courses.

There are high levels of Youtube, Social Networking and the use of Wikipedia than there are in the educational use. It might be useful for supporters of Prensky to concentrate on the use of specific technologies selected by students to support their studies than to use shotgun approach and assume all technologies are used by all students, a regionalisation of users may be a better way to look at 'Digital Natives' perhaps by use of the term@Far Easter digital Natives, or 'UK Digital Natives' rather than just digital natives.

If Prensky was right then the students surveyed would all have the same (or largely so) results not dependent on where they were studying. The survey suggests that since this is not the case, especially with the students from the UK, then we cannot accept that Prensky and his supporters are 100\% correct. There are other influences on the digital natives that need to be taken into account, as some researchers have alluded to in the section on above and Prensky independent. [21] looked at Chinese students at an Australian University and their experiences with online learning. Conclusions drawn from this were that students 'the students' problems in acculturating to their online courses arose at least in part from a clash between their heritage and host educational cultures." so there needs to be an understanding of where the student has been educated or it may be that educators are 'pushing' technology to students where there culture has not supported this type of technology use in the past.

This work therefore supports the researchers who look at independent factors, parent's education, culture, regional preference for technology in the influence on the digital natives.

\section{Conclusions}

It is clear from the findings that there are differences in technology use in the three institutions studied. One of the aims of this work was to answer 'do digital natives in 2012 exist as defined by Prensky?' the answer from this research is that they do not, at least not in the global approach of treating all students as one type of digital native. The second question investigated was 'is there a difference in use of technologies between digital natives of different nationalities?' the answer to this is clearly yes, as students in different countries have different preferences for their use of hardware and software technologies. It is probably time to refine the term 'digital native' and replace it with a more coherent one of 'digital tribes' to take into account the differences between nationalities, pedagogy and the student in Higher Education.

\begin{tabular}{|l|c|c|c|}
\hline \multicolumn{2}{|c|}{ Digital immigrants } & \multicolumn{2}{c|}{} \\
\hline $\begin{array}{c}\text { Baby boomers, } \\
\text { Older boomers }\end{array}$ & Generation X, young boomers & $\begin{array}{c}\text { Digital natives, Generation Y, } \\
\text { Net generation, } \\
\text { Google generation, } \\
\text { millenials }\end{array}$ & $\begin{array}{c}\text { Second generation Digital } \\
\text { natives }\end{array}$ \\
\hline $1945-1964$ & $1965-1981$ & $1982-1995$ & $1996-2013$ \\
\hline
\end{tabular}

Figure 1. Digital natives and their teachers 
Table 1. Findings from the survey

\begin{tabular}{|c|c|c|c|c|c|c|c|}
\hline $\begin{array}{c}\text { Respond } \\
\text { ent } \\
\text { country }\end{array}$ & $\begin{array}{c}\text { Number } \\
\text { of } \\
\text { responde } \\
\text { nts }\end{array}$ & $\begin{array}{c}\text { Averag } \\
\text { e age }\end{array}$ & $\begin{array}{c}\text { Gender male: } \\
\text { female }\end{array}$ & $\begin{array}{c}\text { Average number of } \\
\text { hardware } \\
\text { technologies used } \\
\text { regularly }\end{array}$ & $\begin{array}{c}\text { Average } \\
\text { number of } \\
\text { technologies } \\
\text { used for their } \\
\text { programmes } \\
\text { of study }\end{array}$ & $\begin{array}{c}\text { Average number } \\
\text { of technologies } \\
\text { used for own } \\
\text { learning, but not } \\
\text { provided by their } \\
\text { institution }\end{array}$ & $\begin{array}{c}\text { Osed, not already } \\
\text { included } \\
\text { technologies }\end{array}$ \\
\hline Malaysia & 57 & 21 & $54: 3$ & 3.4 & 13 & 10.6 & 8.0 \\
\hline $\begin{array}{c}\text { South } \\
\text { Korea }\end{array}$ & 56 & 24.9 & $49: 7$ & 3.1 & 14 & 10.7 & 8.4 \\
\hline $\begin{array}{c}\text { United } \\
\text { Kingdom }\end{array}$ & 41 & 22.5 & $25: 16$ & 4.6 & 13 & 11.9 & 7.3 \\
\hline
\end{tabular}

Table 2. Percentage of students having Internet access in their place of residence

\begin{tabular}{|c|c|c|}
\hline Malaysia & South Korea & UK \\
\hline 95 & 100 & 100 \\
\hline
\end{tabular}

Percentage of students accessing the Internet on campus.

\begin{tabular}{|c|c|c|}
\hline Malaysia & South Korea & UK \\
\hline 90 & 98 & 100 \\
\hline
\end{tabular}

Table 3. Percentage of students owning and using on a regular basis

\begin{tabular}{|c|c|c|c|}
\hline & Malaysia & $\begin{array}{c}\text { S. } \\
\text { Korea }\end{array}$ & UK \\
\hline Mobile phone & 85 & 96 & 98 \\
\hline Portable Media Player (e.g. iPod, mp3 player) & 20 & 40 & 67 \\
\hline Personal Computer (e.g. Mac, PC) & 72 & 82 & 75 \\
\hline Handheld Computer (e.g. PDA, Blackberry, Palmtop) & 25 & 1 & 39 \\
\hline Laptop computer & 85 & 66 & 77 \\
\hline Games Console (e.g. Xbox, PlayStation, Nintendo) & 23 & 0 & 52 \\
\hline Portable Games Console (e.g. Gameboy, SonyPSP) & 16 & 0 & 16 \\
\hline Digital Camera & 18 & 19 & 18 \\
\hline Other & 1 & 0 & 3 \\
\hline
\end{tabular}


Table 4. Percentage of students using electronic tools in their course

\begin{tabular}{|c|c|c|c|}
\hline & Malaysia & S. Korea & UK \\
\hline $\begin{array}{c}\text { Course website (e.g. lecture notes, activities, } \\
\text { PowerPoint slides, video clips) }\end{array}$ & 98 & 100 & 90 \\
\hline Online Discussion Groups & 76 & 73 & 72 \\
\hline Virtual/Real Time Chat Facility & 65 & 77 & 49 \\
\hline Video Conferencing & 48 & 46 & 29 \\
\hline Online Assessments (e.g. Multiple choice quizzes) & 71 & 60 & 75 \\
\hline MP3 player & 48 & 55 & 54 \\
\hline Digital Camera & 41 & 57 & 33 \\
\hline Handheld Computer & 57 & 49 & 54 \\
\hline Mobile Phone & 86 & 93 & 88 \\
\hline Podcasts & 35 & 37 & 75 \\
\hline Internet Websites & 98 & 100 & 98 \\
\hline Google/Google Scholar & 95 & 95 & 95 \\
\hline Wikipedia & 95 & 98 & 80 \\
\hline Simulations, games & 81 & 66 & 41 \\
\hline Message Boards & 69 & 93 & 72 \\
\hline Text Messaging & 79 & 91 & 82 \\
\hline MySpace & 20 & 49 & 13 \\
\hline Weblog or Blog & 37 & 66 & 74 \\
\hline YouTube & 76 & 89 & 88 \\
\hline Other(s) & 1 & 0 & 0 \\
\hline
\end{tabular}

Table 5. Percentage of students using electronic tools NOT provided by their University to help them with their studies

\begin{tabular}{|c|c|c|c|}
\hline & Malaysia & S. Korea & UK \\
\hline MySpace & 11 & 24 & 3 \\
\hline Digital Camera & 35 & 44 & 28 \\
\hline Networked PCs/Macs & 72 & 78 & 59 \\
\hline Weblog or Blog & 39 & 64 & 52 \\
\hline Message Boards & 44 & 77 & 52 \\
\hline Mobile Phone & 56 & 69 & 82 \\
\hline Second Life & 32 & 31 & 20 \\
\hline Video/audio clips & 79 & 82 & 62 \\
\hline Internet Websites & 86 & 84 & 92 \\
\hline Podcasts & 30 & 37 & 59 \\
\hline MP3 player & 35 & 47 & 41 \\
\hline Wikipedia & 74 & 73 & 66 \\
\hline Simulations, games & 63 & 42 & 23 \\
\hline Handheld Computer & 63 & 46 & 62 \\
\hline Text Messaging & 67 & 82 & 85 \\
\hline Chat & 70 & 66 & 72 \\
\hline YouTube & 86 & 70 & 70 \\
\hline Google/Google Scholar & 85 & 71 & 85 \\
\hline Other(s) (please give details) & 1 & 0 & 8 \\
\hline
\end{tabular}




\section{Appendix 1}

\section{Survey Questionnaire}

\begin{tabular}{|c|c|c|c|c|c|}
\hline \multicolumn{6}{|c|}{ Section A - Your Personal Details } \\
\hline 1. What is your gender? & \multicolumn{2}{|l|}{ Male } & \multicolumn{3}{|c|}{ Female } \\
\hline \multicolumn{6}{|l|}{ 2. How old are you? } \\
\hline \multicolumn{6}{|l|}{ 3. Nationality } \\
\hline \multicolumn{6}{|l|}{ 4. Home country } \\
\hline \multicolumn{6}{|l|}{ 5. What is your programme of study? } \\
\hline $\begin{array}{l}\text { 6. Do you currently have Internet access in } \\
\text { your place of residence? }\end{array}$ & \multirow{2}{*}{\multicolumn{2}{|c|}{ Yes }} & \multicolumn{3}{|l|}{ No } \\
\hline \multicolumn{4}{|l|}{$\begin{array}{l}\text { 7. Do you access the Internet on campus, and } \\
\text { if so where? }\end{array}$} & & \\
\hline \multicolumn{6}{|c|}{ 8. Which of the following do you own and use regularly ( $3-4$ times per week)? (please tick as many as apply) } \\
\hline \multicolumn{6}{|c|}{\begin{tabular}{|l|l|} 
Mobile Phone & \\
\end{tabular}} \\
\hline \multicolumn{6}{|l|}{ Portable Media Player (e.g. iPod, mp3 player) } \\
\hline \multicolumn{6}{|l|}{ Personal Computer (e.g. Mac, PC) } \\
\hline \multicolumn{6}{|l|}{$\begin{array}{l}\text { Handheld Computer (e.g. PDA, Blackberry, } \\
\text { Palmtop) }\end{array}$} \\
\hline \multicolumn{6}{|l|}{ Laptop computer } \\
\hline \multicolumn{6}{|l|}{$\begin{array}{l}\text { Games Console (e.g. Xbox, Playstation, } \\
\text { Nintendo) }\end{array}$} \\
\hline \multicolumn{6}{|l|}{$\begin{array}{l}\text { Portable Games Console (e.g. Gameboy, } \\
\text { SonyPSP) }\end{array}$} \\
\hline \multicolumn{6}{|l|}{ Digital Camera } \\
\hline \multicolumn{6}{|l|}{ Other(s) (please give details) } \\
\hline \multicolumn{6}{|c|}{ Section B - Use of Technology on Your Programme } \\
\hline \multicolumn{6}{|c|}{ This section concerns your use of technology on your modules for your chosen course of study. } \\
\hline \multicolumn{6}{|c|}{ 9. Please indicate which electronic tools you use in your course and the extent to which you use them } \\
\hline & & daily & weekly & monthly & never \\
\hline \multicolumn{6}{|c|}{$\begin{array}{l}\text { Course website (e.g. lecture notes, activities, PowerPoint slides, video } \\
\text { clips) }\end{array}$} \\
\hline \multicolumn{6}{|l|}{ Online Discussion Groups } \\
\hline \multicolumn{6}{|l|}{ Virtual/Real Time Chat Facility } \\
\hline \multicolumn{6}{|l|}{ Video Conferencing } \\
\hline Online Assessments (e.g. Multiple choice qu & & & & & \\
\hline MP3 player & & & & & \\
\hline Digital Camera & & & & & \\
\hline Handheld Computer & & & & & \\
\hline Mobile Phone & & & & & \\
\hline Podcasts & & & & & \\
\hline Internet Websites & & & & & \\
\hline Google/Google Scholar & & & & & \\
\hline Wikipedia & & & & & \\
\hline Simulations, games & & & & & \\
\hline Message Boards & & & & & \\
\hline Text Messaging & & & & & \\
\hline
\end{tabular}




\begin{tabular}{|l|l|l|l|l|}
\hline MySpace & & & & \\
\hline Weblog or Blog & & & & \\
\hline YouTube & & & & \\
\hline Other(s) (please give details) & & & & \\
\hline
\end{tabular}

Section C - Use of Technology for Your Own Learning communication in relation to your course (e.g. to talk to other students about coursework), but NOT tools provided by your university for the course

10. Please indicate which electronic tools NOT provided by the Universityyou use to help you with your studies (e.g. this may be other software or your own tools and devices.)

\begin{tabular}{|c|c|c|c|c|}
\hline & daily & weekly & monthly & never \\
\hline \multicolumn{5}{|l|}{ MySpace } \\
\hline \multicolumn{5}{|l|}{ Digital Camera } \\
\hline \multicolumn{5}{|l|}{ Networked PCs/Macs } \\
\hline \multicolumn{5}{|l|}{ Weblog or Blog } \\
\hline \multicolumn{5}{|l|}{ Message Boards } \\
\hline \multicolumn{5}{|l|}{ Mobile Phone } \\
\hline \multicolumn{5}{|l|}{ Second Life } \\
\hline \multicolumn{5}{|l|}{ Video/audio clips } \\
\hline \multicolumn{5}{|l|}{ Internet Websites } \\
\hline \multicolumn{5}{|l|}{ Podcasts } \\
\hline \multicolumn{5}{|l|}{ MP3 player } \\
\hline \multicolumn{5}{|l|}{ Wikipedia } \\
\hline \multicolumn{5}{|l|}{ Simulations, games } \\
\hline \multicolumn{5}{|l|}{ Handheld Computer } \\
\hline \multicolumn{5}{|l|}{ Text Messaging } \\
\hline \multicolumn{5}{|l|}{ Chat } \\
\hline \multicolumn{5}{|l|}{ YouTube } \\
\hline \multicolumn{5}{|l|}{ Google/Google Scholar } \\
\hline $\begin{array}{l}\text { Other(s) (please give details) } \\
\text { Any tools you would like to use in your course? }\end{array}$ & & & & \\
\hline
\end{tabular}

\section{Section D - Other Use of Technology/Software other than that detailed above}

11. Please indicate the extent to which you use the following electronic tools, software, websites etc., but NOT in relation to your course or study (i.e. for recreational use), and which particular ones you use.

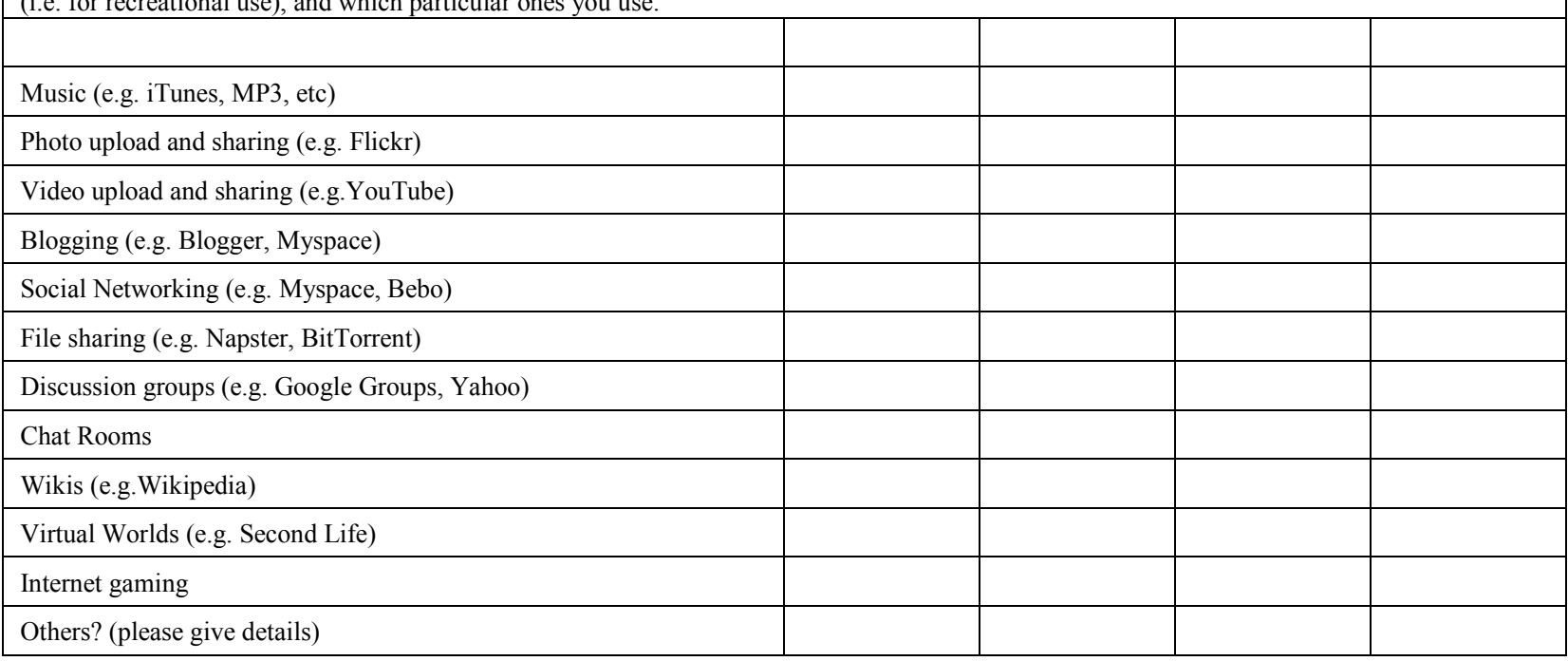




\section{REFERENCES}

[1] M. Prensky. Digital natives, digital immigrants: do they really think differently? On the Horizon, 9 (6), pp. 1-6. 2001

[2] S. Virkus. Use of Web 2.0 technologies in LIS education: experiences at Tallin University, Estonia. Program: electronic library and information systems. Vol. 42 No 3 pp. $262-274$. 2008

[3] N. Herther. Digital Natives and Immigrants What Brain Research tell us. ONLINE Nov/Dec 2009 pp. 15 - 21. 2009

[4] A. Margary, A. Littlejohn, G. Vojt. Are digital natives a myth or reality? University students' use of digital technologies. Computers \& Education Vol.56 Issue 2 pp.429-440 (2011)

[5] E. J. Helsper, R. Eynon. Digital natives: where is the evidence? British Educational Research Journal. Vol. 36, No 3 June 2010 pp. $503-520.2010$

[6] A. Davis. The rise of the digital natives. Digital Media April 2008

[7] M. Gui, G. Argentin. Digital skills of internet natives: Different forms of digital literacy in a random sample of northern Italian high school students. New media and society, 13 (6) pp.963 - 9802011

[8] A.J. Autry, Z. Berge. "Digital natives and digital immigrants: getting to know each other". Industrial and Commercial Training, Vol. 43 Issue: 7 pp. 460 - 466. 2011

[9] M. Robinso. Digital nature and digital nurture: libraries, learning and the digital native. Library Management Vol. 20 No $1 / 2$ pp. $67-76.2008$

[10] S. Bennett, K. Maton, L. Kervin. The 'digital natives'debate: A critical review of the evidence. British Journal of Educational Technology. Vol. 39 No 5 pp. 775- 786. 2008

[11] C. Brown, L. Czerniewicz. Debunking the 'digital native': beyond digital apartheid, towards digital democracy. Journal of Computer Assisted Learning 26 pp. 357 - 369. 2010
[12] Y. Li, M. Ranieri. Are 'digital natives' really digitally competent?-A study on Chinese teenagers.British Journal of Educational Technology Vol. 41 No 6 pp. 1029-1042. 2010

[13] S. Ransdell, B. Kent, S. Gaillard-Kenney J. Long. Digital immigrants fare better than digital natives due to social reliance. British Journal of Educational Technology Vol. 42 No 6. 2011

[14] S. Brabazon, Z. Dear, G. Greene, A. Purdy. Why the Google Generation Will Not Speak: The Invention of Digital Natives. Nebula 6.1 March 2009

[15] P. Rawsthorne, E. Murphy. "Constructivism, Personal Computing Devices and the Internet will continue to have an Influence over Instructional Design." Available at http://www.rawsthorne.org/bit/medit/ed6620/ accessed 5 March 2013

[16] J. Friedl, A. T. Vercic. Media preferences of digital natives internal communication: A pilot study. Public Relations Review 37 pp. $84-86.2011$

[17] L. Corrin, S. Bennett, L. Lockyer, Digital natives: Everyday life versus academic study. Proceedings of the 7 th International Conference on Networked Learning 2010

[18] M. Bullen, T. Morgan, A. Qayyum. Digital Learners in Higher Education: Looking Beyond Stereotypes. In Bastiaens and Ebner (Eds). Proceedings of World Conference on educational Multimedia, Hypermedia and Telecommunications pp. $678-687.2011$

[19] S. Cheryan, A. Meltzoff, S.Kim. Classrooms matter: The design of virtual classrooms influences gender disparities in Computer Science classes. Computers \& Education 57 (2011) pp. 1825-1835. 2011

[20] P. W. Kim, S.Y. Kim, M. Shim, C-H Im, Y-M Shon. The influence of an educational course on language expression andtreatment of gaming addiction for massive multiplayer onlinerole-playing game (MMORPG) players. Computers and Education Vol. 63, p208-217. 2013

[21] R T. H. Chen, S. Bennett, S. When Chinese learners meet constructivist pedagogy Online. High Educ 64 pp677-691. 2012 